Prosiding Seminar Nasional Teknologi Informasi dan Kedirgantaraan : Transformasi Teknologi untuk Mendukung Ketahanan Nasional, Yogyakarta, 13 Desember 2018

SENATIK 2018, Vol. IV, ISBN 978-602-52742-0-6

DOI: http://dx.doi.org/10.28989/senatik.v4i0.262

\title{
MONITORING DEPARTURE TO SCHOOLS IN BASIC SCHOOL STUDENTS USING ARDUINO BASED ON ANDROID Eko Saputro ${ }^{1)}$, Anggraini Kusumaningrum ${ }^{2)}$, Mardiana Irawaty ${ }^{3)}$ \\ Program Studi Informatika \\ Sekolah Tinggi Teknologi Adisutjipto \\ Jl. Janti Blok R Lanud Adisutjipto Yogyakarta \\ Email : ${ }^{1}$ santribackpacker01@gmail.com, ${ }^{2}$ anggraini@ stta.ac.id, ${ }^{3}$ mardiana@stta.ac.id
}

\begin{abstract}
Student departure monitoring is an Android-based app used to monitor student departure to school. This system runs on parent smartphones so parents can see the existence of students and the app will give a message if the student out of the route path that has been set. Arduino used is arduino uno nano type. Arduino programmed using $C$ language, to monitor the existence of students also required some components such as GSM Module and GPS Module. In testing the user application can monitor the existence of the students through the mobile phone that has been installed the application, before monitoring the departure of parents students are required to enter data coordinates home, coordinate data route and data coordinates of schools entered manually. To get the coordinate data the parent can take it through google Maps. To avoid failure in the use of remote control applications should use Android smartphone version 4.1 Jelly bean to version 6.0 Marshmallow. In the experiments this application can run smoothly with the Android version 4.1 to Android version 6.0 and the results of the questionnaire given to the 30 respondents with 9 questions $75.77 \%$ results obtained using Likert-scale calculations, which results obtained a good assessment interval.
\end{abstract}

Keywords: Arduino uno, Smatrphone android, GSM Module, GPS Module.

Abstrak

Monitoring keberangkatan siswa merupakan aplikasi berbasis Android yang digunakan untuk memantau keberangkatan siswa ke sekolah. Sistem ini berjalan di smartphone orang tua sehingga orang tua bisa melihat keberadaaan siswa dan aplikasi akan memberi pesan apabila siswa keluar dari jalur rute yang telah ditetapkan. Arduino yang digunakan merupakan arduino uno tipe nano. Arduino diprogram menggunakan bahasa $\mathrm{C}$, untuk memonitoring keberadaan siswa juga dibutuhkan beberapa komponen seperti Modul GSM dan Modul GPS. Dalam pengujian aplikasi user dapat memantau keberadaan siswa melalui handphone yang telah di install aplikasi tersebut, sebelum memonitoring keberangkatan siswa orang tua diminta untuk memasukkan data koordinat rumah, data koordinat rute dan data koordinat sekolah yang dimasukkan secara manual. Untuk mendapatkan data koordinat tersebut orang tua dapat mengambil melalui google Maps. Untuk menghindari kegagalan dalam penggunaan aplikasi kendali jarak jauh sebaiknya menggunakan smartphone Android versi 4.1 Jelly bean sampai versi 6.0 Marshmallow. Dalam percobaan aplikasi ini dapat berjalan dengan lancar dengan tipe Android versi 4.1 sampai Android versi 6.0 dan pada hasil kuisioner yang diberikan ke pada 30 responden dengan 9 pertanyaan didapat hasil 75,77\% menggunakan perhitungan skala likert, yang mana hasil tersebut mendapat interval penilaian baik.

Kata Kunci : Arduino uno, Smatrphone Android, Modul GSM, Modul GPS 


\section{Pendahuluan}

Ilmu komputer sangat berpengaruh terhadap kehidupan manusia sehingga mendorong manusia untuk membuat hardware dan software yang mendukung perkembangan teknologi dan ilmu komputer dunia yang memudahkan user dalam berkomunikasi dengan komputer. Arduino merupakan pengendali mikro single-board yang bersifat open-source diturunkan melalui Wiring platform dan dirancang untuk memudahkan penggunaan elektronik dalam berbagai bidang. Hardware tersebut memiliki prosesor Atmel AVR dan softwarenya memiliki bahasa pemrograman tersendiri.

Banyak aplikasi yang dapat memonitoring siswa salah satunya dengan menggunakan Device Manager. Aplikasi tersebut digunakan untuk mencari smartphone hilang namun dapat digunakan pula untuk memonitoring siswa dengan syarat siswa membawa smartphone tersebut. Namun, beberapa sekolah memberlakukan peraturan larangan membawa smartphone pada siswa di lingkungan sekolah dasar. Dari permasalahan tersebut dibutuhkan sebuah system yang dapat menampilkan data koordinat dalam peta untuk mengetahui posisi siswa dan memberitahukan kepada orang tua wali jika kendaraan keluar dari jalur/ rute dengan memanfaatkan Arduino dan android.

Beberapa penelitian terdahulu antara lain yang membahas tentang sistem Informasi pemantau penyelewengan kendaraan dinas adalah aplikasi web based yang berfungsi untuk memantau keberadaan kendaraan yang bergerak, sehingga bisa diketahui apakah kendaraan dinas tersebut digunakan secara semestinya atau tidak (ahmad 2013). Erma (2016) dalam penelitiannya tentang prototype alat Lot untuk pemantau kendaraan dibuat dengan Raspberry $P i$ model B dan modul GPS. Roni (2011). Perancangan dimulai dengan mengintegrasikan GPS Tracking dan sensor limit switch.

\section{Metodologi Penelitian}

\subsection{Modul yang digunakan}

Dalam system monitoring kendaraan antar jemput menggunakan Arduino berbasis android menggunakan beberapa modul yaitu:

1. Modul GSM (Global System Mobile) adalah peralatan yang didesain supaya dapat digunakan untuk aplikasi komunikasi dari mesin ke mesin atau dari manusia ke mesin. Modul GSM merupakan peralatan yang digunakan sebagai mesin dalam suatu aplikasi. Dalam aplikasi yang dibuat harus terdapat mikrokontroler yang akan mengirimkan perintah kepada modul GSM berupa AT command melalui RS232 sebagai komponen penghubung (communication links).

2. Arduino adalah sebuah pengendali mikro board tunggal yang memiliki sifat terbuka (open source) yang diturunkan dari platform berbasis Wiring. Pengendali ini dirancang untuk mempermudah penggunaan dalam berbagai bidang elektronik.

3. Android adalah sistem operasi berbasis kernel Linux.Android dikembangkan oleh sebuah perusahaan kecil di silicon valley yang bernama androidinc.

\subsection{Perancangan Sistem}

1. Skema Jaringan

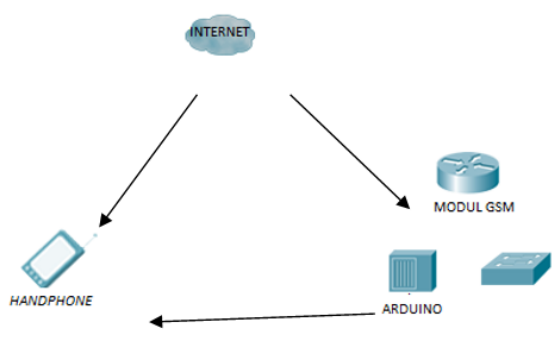

Gambar 1. Skema Jaringan 
Pada Gambar 1 dijelaskan skema jaringan sistem monitoring monitoring kendaraan antar jemput menggunakan Arduino berbasis android. Pada gambar tersebut terdapat smartphone untuk menjalankan sistem, internet dan arduino yang telah ditanamkan modul GSM dan modul GPS .

2. Use Case Diagram

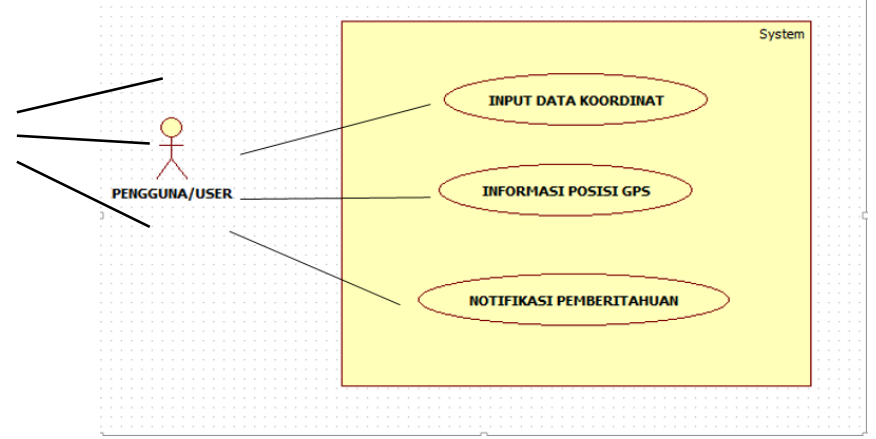

Gambar 2. Use case diagram

Use case diagram mendiskripsikan internal tipikal antara para pengguna sistem dengan sistem itu sendiri, dengan memeberi sebuah narasi bagaimana sistem itu digunakan. Pada Gambar 2 di jelaskan hubungan antara pengguna atau user terhadap sistem, yang mana pengguna dengan menginputkan data koordinat maka sistem akan memberikan informasi posisi keberadaan GPS dan notifikasi pemberitahuan apa bila GPS berada di luar jalur sejauh 500 meter.

3. Activity Diagram

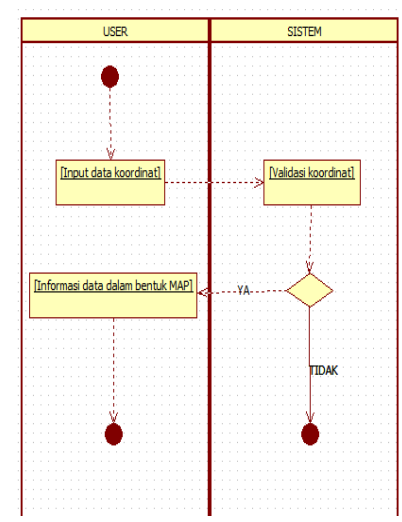

Gambar 3. Activity Diagram Input Data Koordinat

Activity diagram mempunyai fungsi untuk menggabarkan kegiatan yang ada di dalam suatu sistem. Gambar 3 menjelaskan mengenai input data koordinat yang dilakukan pengguna atau user, ketika pengguna membuka aplikasi dan memilih menu input data dan mengisi data koordinat rumah, koordinat rute dan koordinat sekolah yang mana data koordinat tersebut bisa diambil dari aplikasi google map. Ketika data telah diisi dengan benar maka sistem akan menampilkan informasi data dalam bentuk MAP. 


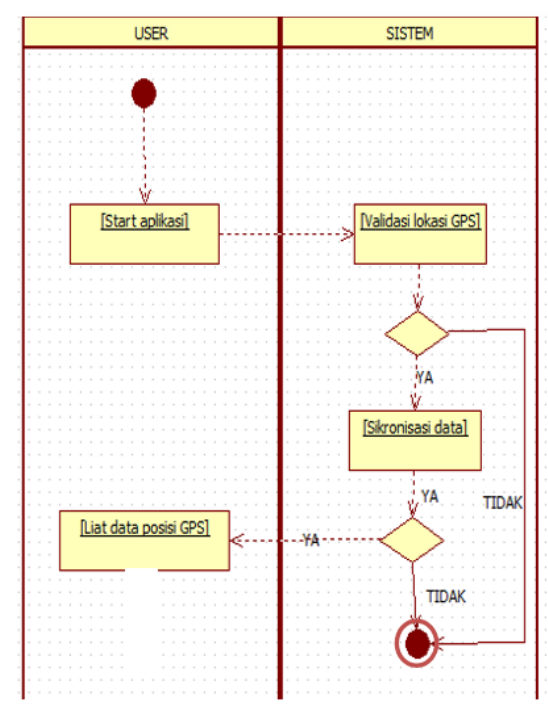

Gambar 4. Activity Diagram Lihat Lokasi GPS

Gambar 4 menjelaskan tentang alur user melihat lokasi siswa yang telah diletakkan alat atau Arduino. User akan dapat melihat melalui aplikasi Android di mana keberadaaan siswa.

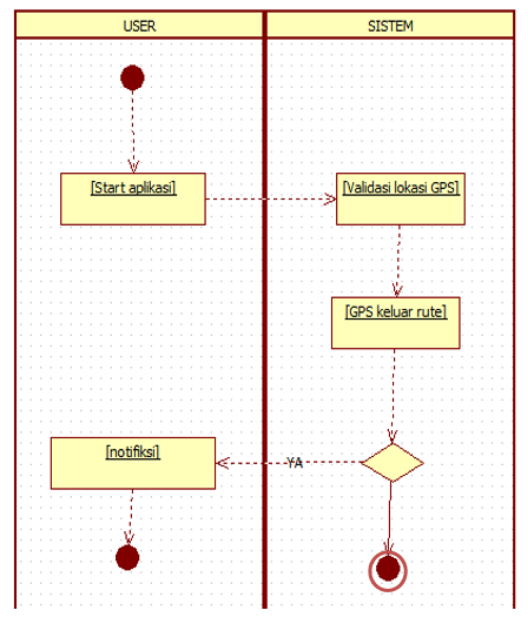

Gambar 5. Activity Diagram Notifikasi

Gambar 5 menjelaskan tentang alur notifikasi yang akan di terima oleh user. Sistem akan memperoses apa bila GPS keluar dari rute yang telah ditentukan sejauh 500 meter maka sistem akan mengirimkan notifikasi ke Android, bertujuan agar user mengetahui bahwa siswa tersebut jalan tidak pada rutenya. 
4. Sequensial Diagram

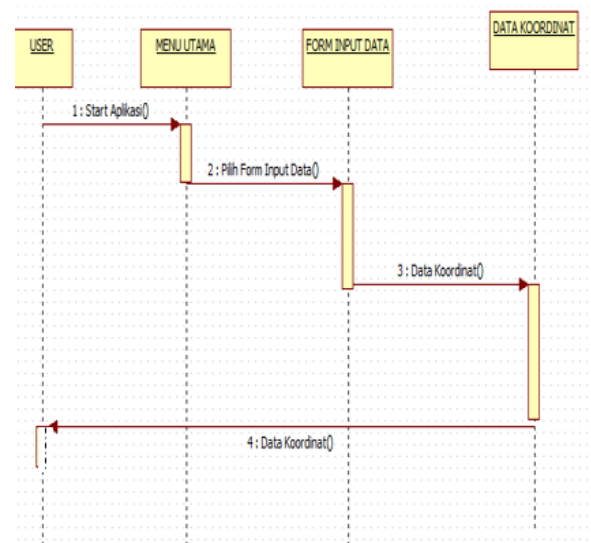

Gambar 6. Sequence Diagram Input Data

Gambar 6 menjelaskan alur sequence diagram input data, user menjalankan aplikasi dan memiilih menu untuk menginput data koordinat rumah, rute, dan sekolah. Setelah user menginput data koordinat maka aplikasi akan member informasi koordinat pada maps atau peta.

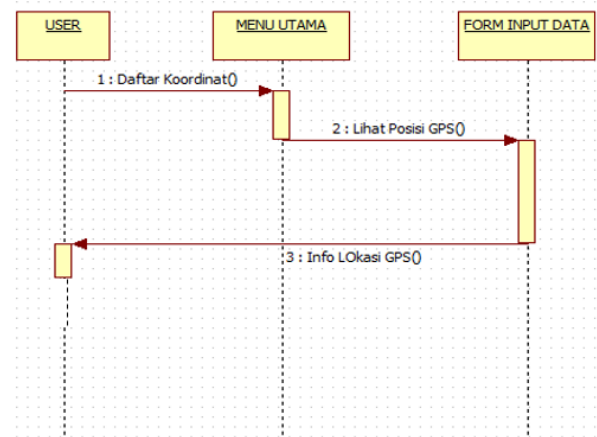

Gambar 7. Sequence Diagram Liat Posisi GPS

Gambar 7 menjelaskan alur sequence diagram liat posisi GPS, ketika user telah memasukkan koordinat yang telah diminta sistem maka sistem akan mengirimkan data keberadaan GPS berada, yang mana data tersebut di kirim melalui alat.

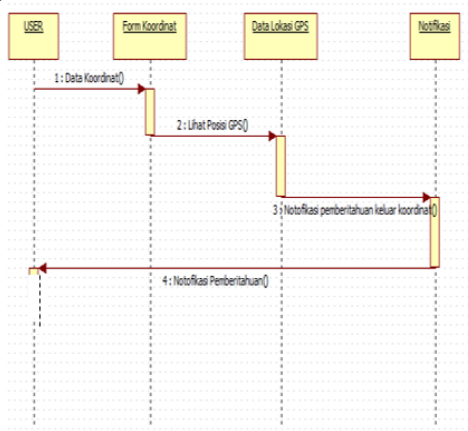

Gambar 8. Sequence Diagram Notifikasi Pemberitahuan

Gambar 8 menjelaskan alur sequence diagram notifikasi, user memasukkan data koordinat dan sistem akan menampilkan posisi keberadaan GPS. Ketika GPS keluar dari koordinat yang telah ditentukan maka sistem akan member notifikasi pada user.

\section{Hasil dan Pembahasan}

Aplikasi ini memanfaatkan arduino uno sebagai media utama dalam melakukan aksi 
mengontrol keberangkatan siswa. Di dalam arduino tersebut ada beberapa komponen seperti PCB (Printed Circuit Board), Modul GSM (Global System Mobile) dan modul GPS(Global Positioning System) yang saling berterkaitan antara satu dengan yang lain, sehingga apabila sala satu dari kedua komponen tersebut tidak berfungsi maka arduino tidak dapat mengirim data posisi siswa. Aplikasi ini memiliki fungsi untuk me-monitoring keberadaan siswa, mensetting koordinat rumah, koordinat rute dan koordinat sekolah.

\subsection{Pengujian Melihat Posisi Keberadaan Siswa}

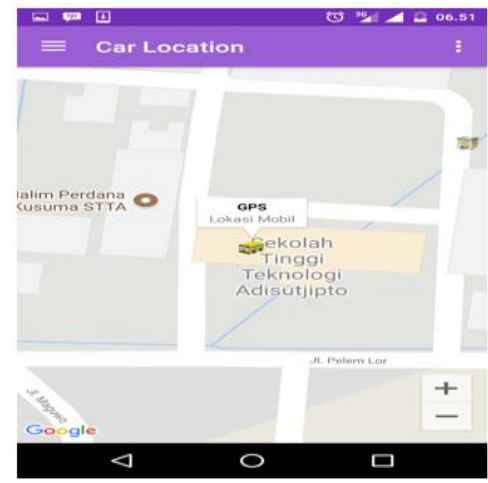

Gambar 8 posisi GPS

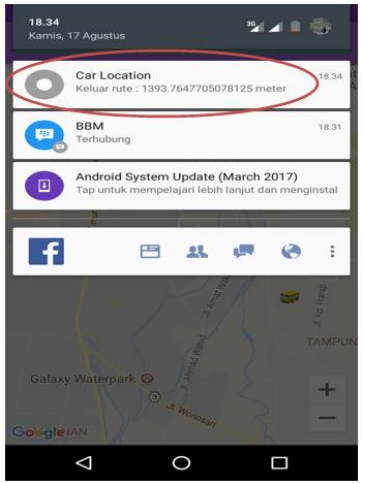

Gambar 9. Notifikasi keluar jalur

Pada Gambar 8 menjelaskan ketika user telah menginputkan data koordinat rumah, data koordinat rute dan data koordinat sekolah pada form input data koordinat maka aplikasi akan menampilkan data inputan tersebut dalam bentuk MAP dan monitoring pada alat sudah bisa dilakukan. Aplikasi dapat memonitoring alat apabila alat telah dinyalakan dan memiliki data internet. Apabila siswa keluar dari rute yang telah di tentukan maka aplikasi akan memberikan notifikasi pemberitahuan bahwa siswa tersebut berada di luar rute sejauh 500 meter. Berikut notifikasi pemberitahuan dapat dilihat pada Gambar 9.

\subsection{Pengujian Smartphone Android}

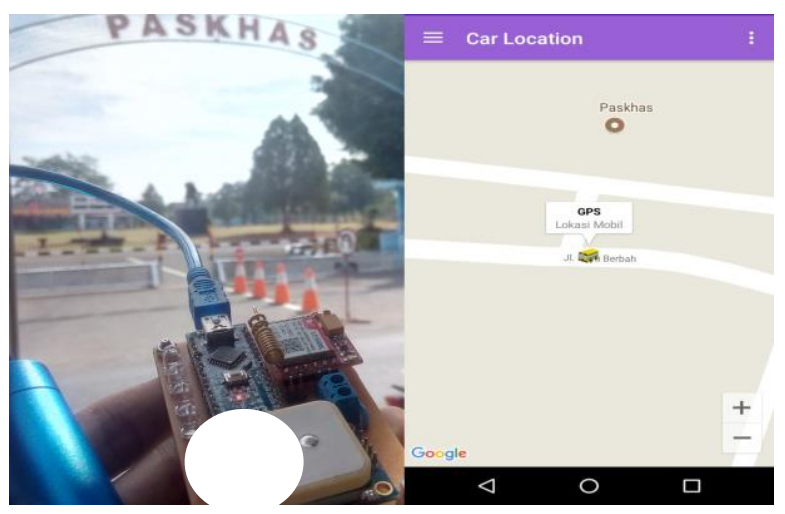

Gambar 10. Ketepatan posisi GPS dengan alikasi

Pada Gambar 10 dijelaskan bahwa GPS dengan aplikasi harus sikron agar menunjukkan ke validan pada data. Pada gambar 4.9 disitu alat berada di depan lapangan PASKHAS dan pada aplikasi juga menampilkan keberadaan GPS berada di depan PASKHAS. 


\subsection{Pengujian Ketepatan Posisi GPS Dengan Aplikasi}

Dalam uji coba user menggunakan beberapa versi android yang berbeda dengan spesifikasi smartphone yang berbeda dan merk yang bebrbeda. Mulai dari smartphone android merk Xiaomi, Samsung, Lenovo, Infinix hot, Oppo, Asus dan smartfrent. Pada pengujian ini semua smartphone android menggunakan aplikasi dan mencoba menjalankan aplikasi tersebut apakan dapat berjalan dengan lancar. Dalam pengujian tersebut user melakukan uji coba melalui 20 smartphone android dari spesifikasi, merk serta versi smartphone android yang berbeda. Berikut adalah tabel tampilan pengujian smartphone android memonitoring keberangkatan ke sekolah pada siswa sekolah dasar dapat di lihat pada Tabel 1.

Tabel 1 Pengujian smartphone android pada aplikasi monitoring keberangkatan

\begin{tabular}{|c|c|c|c|c|c|}
\hline NO & $\begin{array}{c}\text { Merk } \\
\text { Smartphone }\end{array}$ & Versi Smartphone & $\begin{array}{c}\text { Berjalan } \\
\text { disistem }\end{array}$ & $\begin{array}{l}\text { GPS } \\
\text { berjalan }\end{array}$ & $\begin{array}{c}\text { Melihat } \\
\text { posisi }\end{array}$ \\
\hline 1 & Lenovo A1900 & $\begin{array}{c}\text { Versi 4.4.2 } \\
\text { (KitKat) }\end{array}$ & $\sqrt{ }$ & $\sqrt{ }$ & $\sqrt{ }$ \\
\hline 2 & Xiaomi redmi 1S & $\begin{array}{c}\text { Versi 4.4.4 } \\
\text { (Jelly Bean) }\end{array}$ & $\sqrt{ }$ & $\sqrt{ }$ & $\sqrt{ }$ \\
\hline 3 & Lenovo A6000 & $\begin{array}{c}\text { Versi 4.4.4 } \\
\text { (Jelly Bean) }\end{array}$ & $\sqrt{ }$ & $\sqrt{ }$ & $\sqrt{ }$ \\
\hline 4 & Lenovo A2010 & $\begin{array}{c}\text { Versi 5.1 } \\
\text { (Lollipop) }\end{array}$ & $\sqrt{ }$ & $\sqrt{ }$ & $\sqrt{ }$ \\
\hline 5 & Oppo A 37 & $\begin{array}{c}\text { Versi 5.1 } \\
\text { (Lollipop) }\end{array}$ & $\sqrt{ }$ & $\sqrt{ }$ & $\sqrt{ }$ \\
\hline
\end{tabular}

$$
\text { Keterangan: } \quad \begin{aligned}
\sqrt{ } & =\text { Berhasil } \\
& X=\text { Gagal }
\end{aligned}
$$

\subsection{Uji Pengguna}

Uji coba pengguna aplikasi Monitoring Aktivitas di Jejaring Sosial dilakukan dengan menggunakan kuesioner yang dihitung berdasarkan metode Skala Likert. Dimana setiap pertanyaan memiliki 5 pilihan jawaban, dengan memberikan skor pada setiap jawaban, yaitu jawaban sangat baik (SB) bernilai skor 5, jawaban baik (B) bernilai skor 4, jawaban cukup (C) bernilai skor 3, jawaban kurang (K) bernilai skor 2 dan jawaban sangat kurang (SK) bernilai skor 1 .

Tabel 2. Interval Penilaian

\begin{tabular}{|l|l|}
\hline Angka & Keterangan \\
\hline $0 \%-19,9 \%$ & Sangat Kurang \\
\hline $20 \%-39,9 \%$ & Kurang \\
\hline $40 \%-59,9 \%$ & Cukup \\
\hline $60 \%-79,9 \%$ & Baik \\
\hline $80 \%-100 \%$ & Sangat Baik \\
\hline
\end{tabular}

Pada kuesioner ini terdiri dari 9 pertanyaan mengenai tampilan dan kerja dari sistem. Berikut ini adalah hasil yang didapat dari kuesioner yang dihitung menggunakan metode skala likert terlihat pada Tabel 3. 
Tabel 3. Hasil Total Responden pada Pengujian Sistem

\begin{tabular}{|c|c|c|c|c|c|c|c|}
\hline \multirow{2}{*}{ Pertanyaan } & \multicolumn{5}{|c|}{ Penilaian } & \multirow{2}{*}{ Total Skor } & \multirow{2}{*}{ Persentase $\%$} \\
\hline & SB & B & $\mathrm{C}$ & K & SK & & \\
\hline 1 & 3 & 20 & 7 & 0 & 0 & 116 & $77,33 \%$ \\
\hline 2 & 1 & 22 & 7 & 0 & 0 & 114 & $76 \%$ \\
\hline 3 & 4 & 13 & 9 & 4 & 0 & 102 & $68 \%$ \\
\hline 4 & 3 & 19 & 8 & 0 & 0 & 115 & $76,66 \%$ \\
\hline 5 & 5 & 16 & 7 & 2 & 0 & 114 & $76 \%$ \\
\hline 6 & 4 & 12 & 14 & 0 & 0 & 110 & $73,33 \%$ \\
\hline 7 & 5 & 17 & 8 & 0 & 0 & 117 & $88 \%$ \\
\hline 8 & 11 & 12 & 7 & 0 & 0 & 124 & $82,66 \%$ \\
\hline 9 & 5 & 13 & 10 & 2 & 0 & 111 & $74 \%$ \\
\hline \multicolumn{7}{|c|}{ Total Persentase } & $681,98 \%$ \\
\hline \multicolumn{7}{|c|}{ Rata-rata } & $75,77 \%$ \\
\hline
\end{tabular}

Pada tabel 3 Hasil total pada responden pada pengujian sistem terisi 30 responden. Rumus perhitungan persentase tiap jawaban dan perhitungan rata-rata pada hasil uji pengguna adalah sebagai berikut :

Rumus index $\%=$ Total skor $/ \mathrm{Y}$ x 100

Maka penyelesaian akhir dari kasus ini adalah:

$=$ Total skor $/ \mathrm{Y}$ x 100

$=1023 / 1350 \times 100$

$=75,77 \%$

\section{Kesimpulan}

Dari penelitian ini dapat disimpulkan sebagai berikut :

1. Aplikasi ini memanfaatkan arduino uno yang digunakan sebagai media utama dalam melakukan montoring keberadaan siswa.

2. Aplikasi ini telah diuji dan dapat digunakan untuk memonitoring keberangkatan ke sekolah pada siswa yang ada didalam smartphone android.

3. Aplikasi monitoring siswa telah melakukan pengujian di smartphone android mulai dari versi 4.1 KitKat sampai versi Versi 6.0 Marshmallow dan dinyatakan berhasil.

4. Aplikasi ini dapat memproses data koordinat dan menampilkan dalam bentuk Maps.

5. Aplikasi ini dapat menjadi solusi atas kesibukan orangtua dalam hal mengontrol keberangkatan siswanya menuju sekolah.

\section{Daftar Pustaka}

[1] Rifai, A. (2013). Sistem Informasi Pemantauan Posisi Kendaraan Dinas Unsri Menggunakan Teknologi GPS. Jurnal Sistem Informasi, 5(2). 
[2] Susanti, E., \& Triyono, J. (2016). Prototype Alat IoT (Internet Of Things) untuk Pengendali dan Pemantau Kendaraan Secara Realtime.

[3] Zakaria, R., \& Hardono, Y. A. (2011). Perancangan Sistem Keamanan Berbasis Limit Switch Sensor dan GPS Tracking System Bagi Penyedia Jasa Layanan Pengiriman Barang: Studi Kasus. PERFORMA: Media Ilmiah Teknik Industri, 10(1).

[4] Kadir, A. (2014). From Zero To A Pro: Pemrograman Aplikasi Android. Yogyakarta: Andi.

[5] Kadir, A. (2013). Panduan Praktis Mempelajari aplikasi mikrokontroler dan pemrogramannya menggunakan Arduino. Yogyakarta: Andi.

[6] Satyaputra, A., Aritonang, E. M., \& Kom, S. (2016). Lets Build Your Android Apps with Android Studio. Elex Media Komputindo.

[7] Azzami, W., Kusumaningrum, A., \& Sudaryanto, S. (2018). PEMANFAATAN GEOFENCE UNTUK MENCARI LOKASI BENGKEL TAMBAL BAN TERDEKAT BERBASIS ANDROID. Compiler, 7(1).

[8] Kusumaningrum, A., Pujiastuti, A., \& Zeny, M. (2017). Pemanfaatan Internet Of Things pada Kendali Lampu. Compiler, 6(1).

[9] Wintolo, H., Sudaryanto, S., \& Pramudito, C. G. (2018). Remote Camera For Android Based Smartphones Installed On The Syma X8HG Drone. Angkasa: Jurnal Ilmiah Bidang Teknologi, 10(2). 